\title{
Bandwidth Enhancement of Microstrip Patch Antenna
}

\author{
Ahmad Al-Ahmadi ${ }^{1} \&$ Yahya S. H. Khraisat ${ }^{1}$ \\ ${ }^{1}$ Department of Electrical Engineering, Faculty of Engineering, Taif University, KSA \\ Correspondence: Yahya S. H. Khraisat, Department of Electrical Engineering, Faculty of Engineering, Taif \\ University, KSA. E-mail: yskhraisat@tu.edu.sa
}

Received: October 6, 2018

Accepted: October 20, 2018

Online Published: January 29, 2019

doi:10.5539/apr.v11n1p35

URL: https://doi.org/10.5539/apr.v11n1p35

\begin{abstract}
Microstrip patch antenna (MPA) is suitable for different applications in wireless communications. MPA suffers from low gain and narrow bandwidth. In this paper we improved its bandwidth by inserting multiple slots in its ground plane. We used FR-4 substrate to design this antenna. The dimensions of this antenna are $60 \mathrm{~mm}$ and $80 \mathrm{~mm}$. The dielectric constant is equal to 4.4 and the height is $1.6 \mathrm{~mm}$. We inserted up to 12 slots in ground plane with $1 \mathrm{~mm}$ width. The spacing between slots is $3 \mathrm{~mm}$ slots were arranged parallel to the feeding line. Simulation was done using HFSS simulator.
\end{abstract}

Keywords: Microstrip Patch Antenna, Bandwidth, Gain, Ground Slots and HFSS Simulator

\section{Introduction}

Communication systems deals with transmitting information bearing signals through channel from transmitter to the receiver. The antenna is used in both transmitting and receiving parts of communication system to convert voltage or current into electromagnetic signals during transmission and vice versa during reception. MPA are commonly used in different Communication systems because of their small size, high gain and their wide coverage pattern. One of their disadvantages which limits there widely implementation is narrow bandwidth. MPA are used in different applications like wireless communication including mobile systems. They are also used in computer links, remote controls and satellite communication systems. MPA usually consists of a radiating patch which is made of conducting material such as gold or copper. It can take any possible shape rectangular, triangular, square, or circle (Khraisat, Olaimat, \& Abdel-Razeq, 2012). The radiating patch and the feed lines are usually inserted on the dielectric substrate as shown in Figure 1.

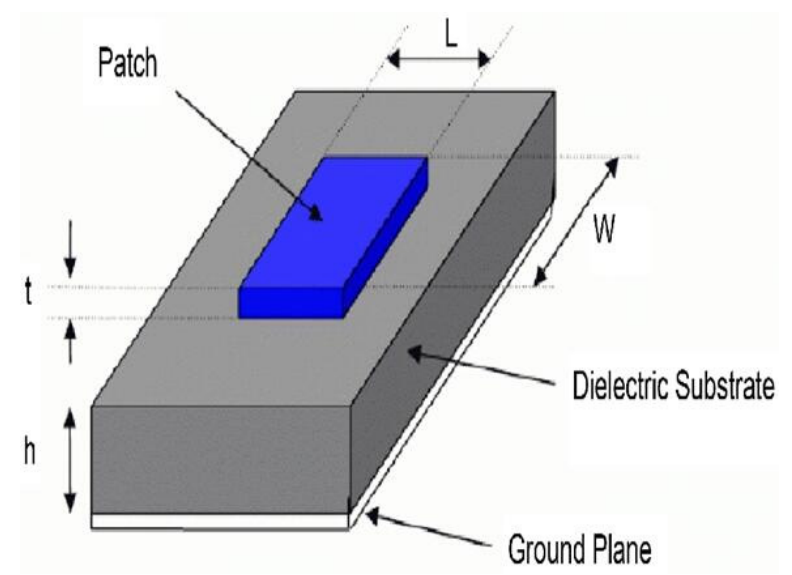

Figure 1. Structure of a microstrip patch antenna

In (Thakare \& Singhal, 2009), authors inserted slots into MPA to improve its bandwidth. They demonstrated the design of slotted microstrip antenna on a substrate of thickness $1.588 \mathrm{~mm}$ that gives wideband characteristics. The illustrated patch antenna provides bandwidth enhancement compared to antenna without slots of the same physical dimensions. The simulation was obtained by using IE3D simulator. 
In (Roy, Môm, \& Igwue, 2013), three different geometry shapes, the U, E and H were developed from a rectangular patch of width $(\mathrm{W})=32 \mathrm{~mm}$ and length $(\mathrm{L})=24 \mathrm{~mm}$. Bandwidth improvement by $4.81 \%$ for 100MHZ, $28.89 \%$ for $610 \mathrm{MHz}, 9.13 \%$ for $630 \mathrm{MHz}$ and $9.13 \%$ for $110 \mathrm{MHz}$.

In (Abu Tarboush, Al-Raweshidy, \& Nilavalon, 2009), authors improved antenna bandwidth by $25 \%$ which was obtained by inserting slots on ground plane and stacked patch supported by wall. This design doesn't affect the frequency of operation. In (Liu, Cheung, \& Yuk, 2011), Slots of different shapes triangular or rectangular were placed on the ground plane under the feed line of the radiator for bandwidth improvement and impedance matching.

\section{Antenna Design Procedure}

We investigated rectangular MPA with and without slots on FR-4 dielectric substrate. The dielectric constant was 4.4 , substrate height was $1.6 \mathrm{~mm}$. The antenna developed on a substrate of dimension $60 \mathrm{~mm} \times 80 \mathrm{~mm}$. Values of different parameters which we used in antenna design are shown in Table 1.

Table 1. Antenna Parameters

\begin{tabular}{ll}
\hline Parameters & Numerical Values \\
\hline Substrate length & $80 \mathrm{~mm}$ \\
Substrate width & $60 \mathrm{~mm}$ \\
Substrate height & $1.6 \mathrm{~mm}$ \\
Patch length & $50 \mathrm{~mm}$ \\
Patch width & $41 \mathrm{~mm}$ \\
Feeding length & $17 \mathrm{~mm}$ \\
Feeding width & $3.5 \mathrm{~mm}$ \\
Slot width & $1 \mathrm{~mm}$ \\
\hline
\end{tabular}

The shape of rectangular MPA with inset feed is shown in Figure 2.

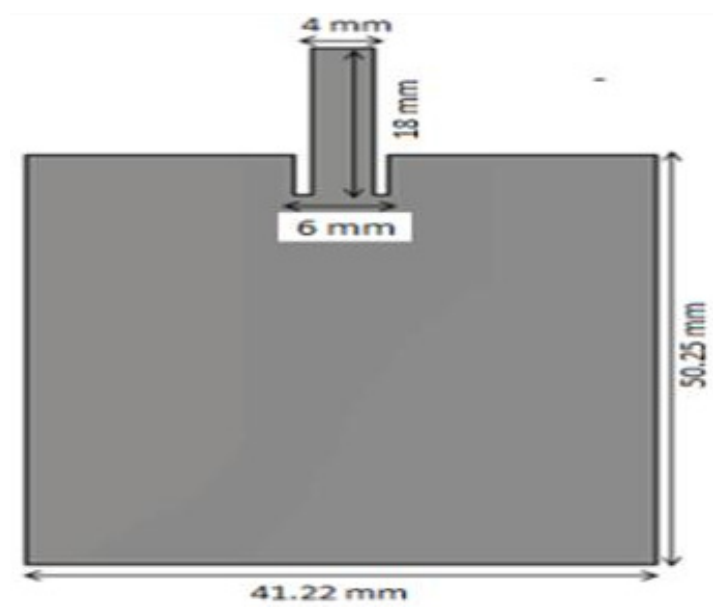

Figure 2. Rectangular Patch Antenna

Rectangular Microstrip patch was designed with $\mathrm{gr}=4.4$ and $\mathrm{h}=1.6 \mathrm{~mm}$. The patch was designed for $2.4 \mathrm{GHz}$, with dielectric substrate of thickness ' $h$ ', and relative dielectric constant $\varepsilon r$. The width and length of the patch can be calculated by

$$
W=c / 2 f\left[\frac{\varepsilon_{r}+1}{2}\right]^{\frac{-1}{2}}
$$

and

$$
L=\frac{c}{2 f \sqrt{\varepsilon_{e}}}-2 \Delta I
$$

The antenna was designed using HFSS. 


\section{Slot in the Ground Plane of Rectangular Patch}

They are different methods by which slots are inserted into MPA. In (Liu, Cheung, \& Yuk, 2011), three slots in the ground plane were designed as shown in Figure 3. The three slots were made along the axis of resonating length. Two slots were inserted in one side of the patch and third one was inserted in other side. This antenna was investigated by changing slots length and width in the ground plane. The antenna has a rectangular radiating patch of dimensions $\mathrm{L} \times \mathrm{W}$. Three identical slots were inserted in the antennas ground plane and aligned with an equal spacing of $\mathrm{L} / 4$ and in parallel with the patches radiating edges or the y-axis. In this design the slot width was $2 \mathrm{~mm}$. The microstrip patchwas fed coaxially at distance L/4 from the center of the non-radiating edge for good impedance matching purposes.
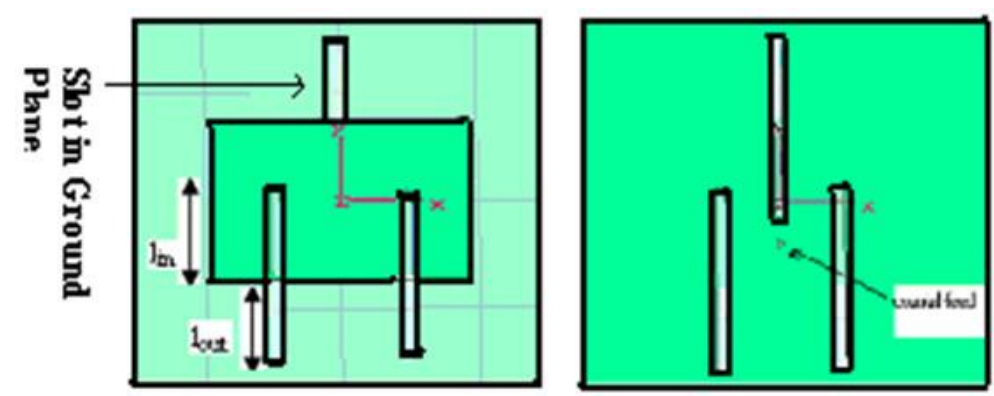

Figure 3. Microstrip Rectangular Patch

Nearly square microstrip Patch was developed on a FR4 substrate with $\varepsilon r=4.3$ and $\mathrm{h}=1.6 \mathrm{~mm}$ with aspect ratio $=0.985$. The microstrip patch was fed coaxially at position $(-4.5,-5.5) \mathrm{mm}$ along the diagonal as shown in Figure 4. The 4 slots were etched in patch. The effect of slots were studied by changing the length and the width of the slot. This design taked into account the measurements of impedance, bandwidth, half power beam width, gain and efficiency.

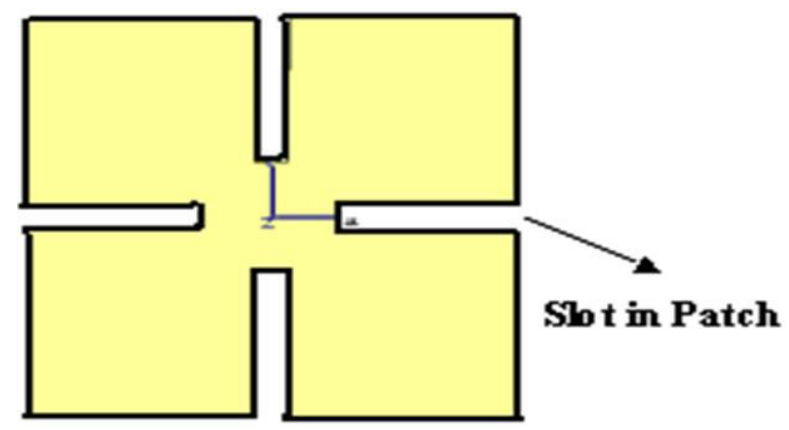

Figure 4. Square Microstrip Patch with Four Slots

We investigated MPA with multiple number of slots. We added 12 slots in the ground plane with $3 \mathrm{~mm}$ spacing. The width of each slot was $1 \mathrm{~mm}$. All slots were arranged in parallel to the feeding line. Each slot line is $2 \mathrm{~mm}$ shorter than previous one. The design is shown in Figure 5.

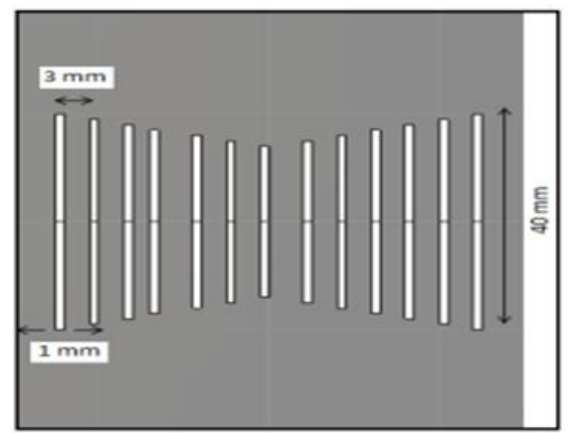

Figure 5. Microstrip patch antenna slots in ground plane 
The formulas used to calculate the length and width of patch are shown below

$$
\begin{gathered}
\varepsilon_{\text {reff }}=\frac{\epsilon_{r}+1}{2}+\frac{\epsilon_{r}-1}{2} \sqrt{1+12(h / w)} \\
\Delta L=0.412 h \frac{\left(\varepsilon_{r e f f}+0.33\right)\left(\frac{w}{h}+0.264\right)}{\left(\varepsilon_{\text {reff }}-0.258\right)\left(\frac{w}{h}+0.8\right)}
\end{gathered}
$$

\section{Simulation and Results}

The proposed antenna was simulated by HFSS (High Frequency Structure Simulator) as shown in Figures 6 and 7.

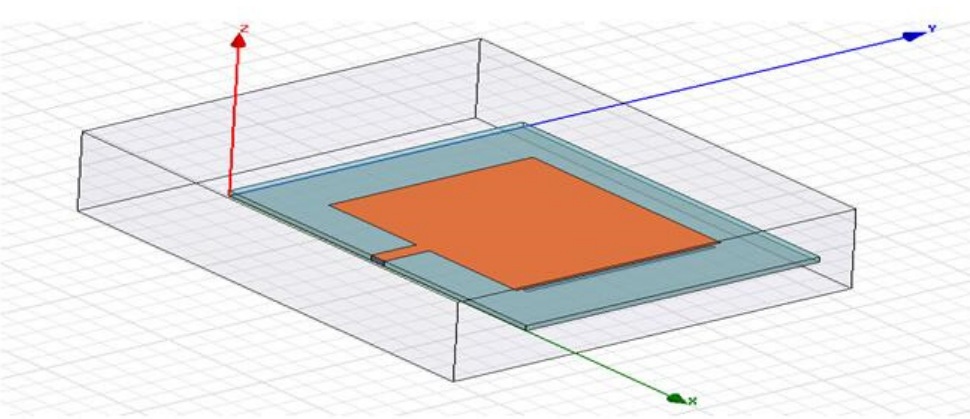

Figure 6. Microstrip patch antenna design

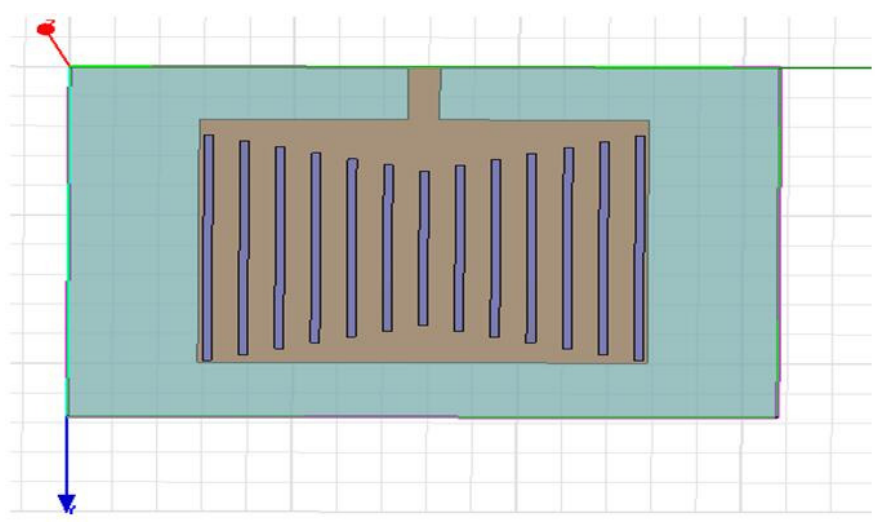

Figure 7. Design of slots in the ground plane

Return loss characteristics Results of the designed MPA is shown below in Figure 8.

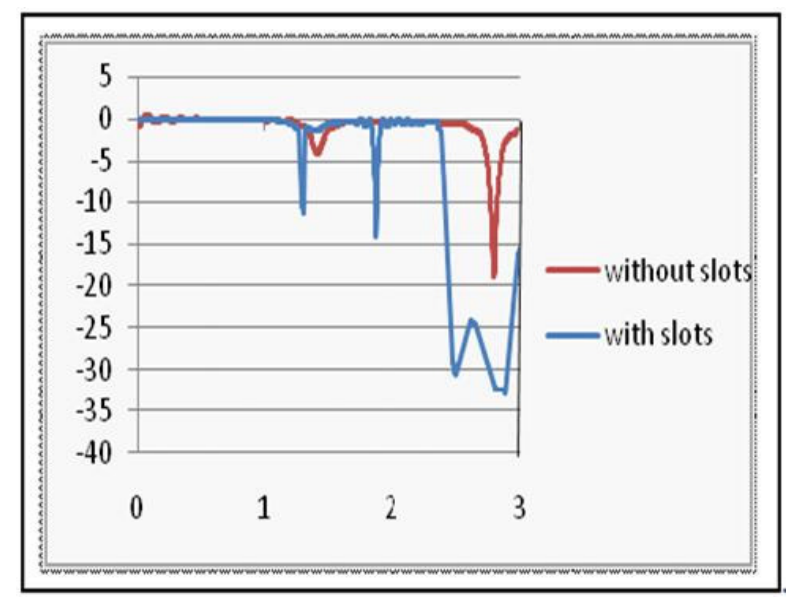

Figure 8. Comparison of return loss characteristics of the patch antenna with and without slots 
Comparison was made for the case of inserting slots with the case of no slots as shown in Figure 8.

We noticed that the conventional patch antenna without slot exhibit only one resonant frequency at $2.75 \mathrm{GHz}$, whereas antenna with slots exhibits multiple number of resonant frequencies: at $1.35 \mathrm{GHz}$ and $1.75 \mathrm{GHz}$. Wide band response was obtained from $2.43 \mathrm{GHz}$ to $2.97 \mathrm{GHz}$.

The bandwidth of patch antenna without slot was $47 \mathrm{MHz}$, whereas the bandwidth of the same antenna with slot was $540 \mathrm{MHz}$. The bandwidth of patch antenna with slot was enhanced approximately $493 \mathrm{MHz}$ with respect to conventional antenna.

The variation of far field properties of patch antenna with and without slots are shown in Figures 9 and 10.

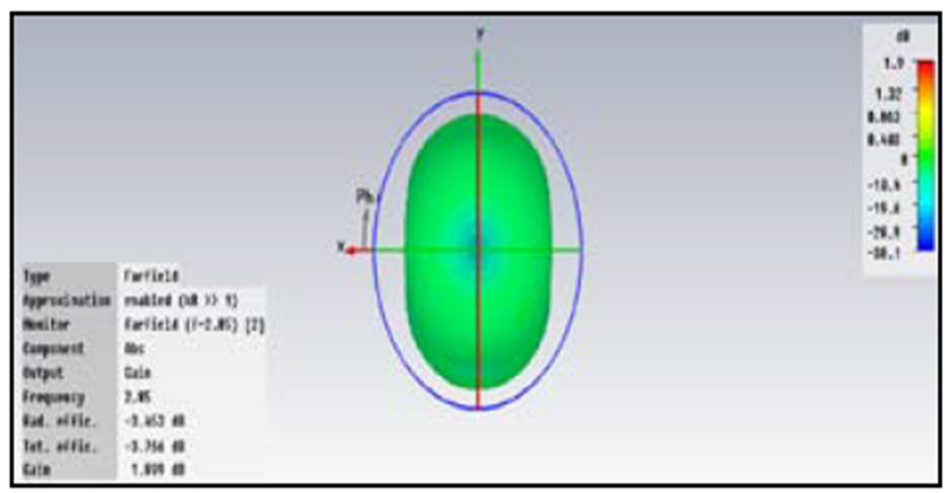

Figure 9. Far field pattern of patch antenna with slot

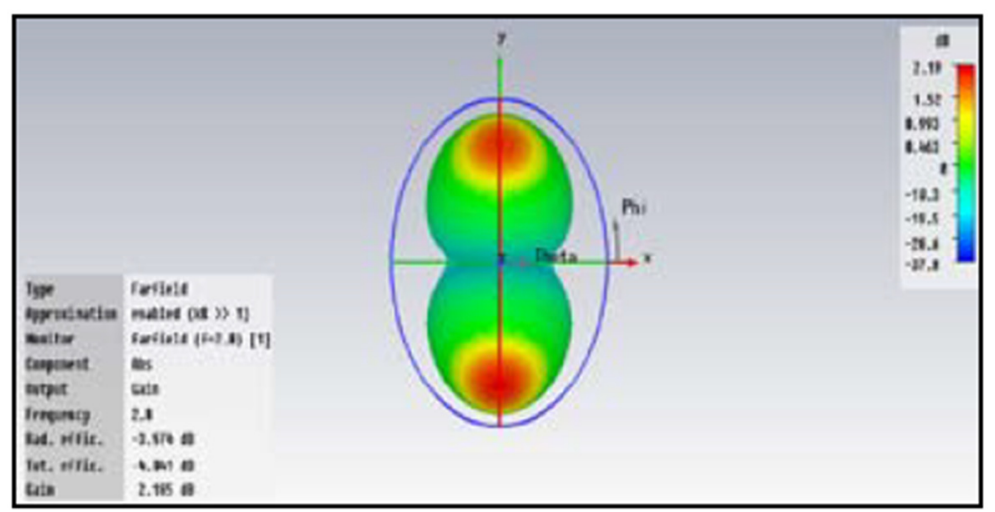

Figure 10. Far field pattern of conventional patch antenna

From the above Figures it can be seen that the gain and directivity with and without slots were not affected. The gain of patch antenna with and without slots is $1.899 \mathrm{~dB}$ and $2.185 \mathrm{~dB}$ respectively. The directivity of the patch antenna with and without slots is $5.353 \mathrm{dBi}$ and $6.159 \mathrm{dBi}$ respectively.

\section{Conclusion}

The bandwidth of the MPA has been improved using multiple numbers of slots in the ground plane. The multiple bands and a wide band response are achieved by using this technique.

The antenna with slots shows bandwidth up to $540 \mathrm{MHz}$ compared to the conventional one which was only $47 \mathrm{MHz}$. However, it can be concluded that the proposed design can be also implemented for other shapes of patch antennas.

\section{Conflict of interests}

The authors declare that there is no conflict of interests regarding the publication of this paper.

\section{References}

Abu Tarboush, H. F., Al-Raweshidy, H. S., \& Nilavalon, R. (2009). Bandwidth Enhancement for Microstrip Patch Antenna Using Stacked Patch and Slot. Antenna Technology 2009 IWAT 2009 IEEE International Workshop. 
Khraisat, Y. S. H., Olaimat, M. M., \& Abdel-Razeq, S. N. (2012, May). Comparison Between Rectangular and Triangular Patch Antennas Arrays. Applied Physics Research, 4(2), 75-81.

Liu, L., Cheung, S. W., \& Yuk, T. I. (2011). Bandwidth Improvements Using Ground Slots for Compact UWB Microstrip-fed Antennas. PIERS Proceedings, Suzhou, China, September 12-16. Retrieved from https://www.researchgate.net/publication.229020896;

https://www.ijircce.com/upload/2015/april/34_Design.pdf; https://en.wikipedia.org/wiki/Microstrip

Roy, A. A., Môm, J. M., \& Igwue, G. A. (2013). Enhancing the Bandwidth of a Microstrip Patch Antenna Using Slots Shaped Patch. American Journal of Engineering Research (AJER), 2(9), 23-30.

Thakare, V. V., \& Singhal, P. K. (2009). Bandwidth Analysis By Introducing Slots Microstrip Antenna Design Using Ann. Progress In Electromagnetics Research M.

\section{Copyrights}

Copyright for this article is retained by the author(s), with first publication rights granted to the journal.

This is an open-access article distributed under the terms and conditions of the Creative Commons Attribution license (http://creativecommons.org/licenses/by/4.0/). 